\title{
INFLUÊNCIA DA ÉPOCA DE PLANTIO NA PRODUÇÃO DE CLASSES DE BULBOS COMERCIAIS DE CULTIVARES DE ALHO (Allíum sativum L.) EM SANTA MARIA, RS
}

\author{
PLANTING DATE INFLUENCE ON THE YIELD OF BULB QUALITY GRADES \\ OF GARLIC (Ailium sativum L.) CULTIVARS IN SANTA MARIA, RS
}

\section{Jorge Nadir Trevisan ${ }^{1}$ Gustavo Adolfo Klippel Martins ${ }^{2}$ Nara Rejane Zamberlan dos Santos ${ }^{3}$}

RESUMO

O experimento foi conduzido na Universidade Federal de Santa Maria, RS, no ano agrícola de 1984, para avaliar a influência de três épocas de plantio no rendimento de bulbos comerciais e de classes de bulbos de 10 cultivares de alho (Allíum sativum L.). As épocas de plantio influenciaram o rendimento médio de bulbos comerciais e de classes de bulbos. $O$ plantio de 18/5 agregou incremento no rendimento de bulbos comerciais, tendo sido o mais alto do experimento. As cultivares Gigante Lavínia, Gigante Inconfidentes, São Lourenço e Quitéria apresentaram o melhor desempenho produtivo.

Palavras-chave: alho, cultivares, plantio, épocas, rendimento, bulbos comerciais.

\section{SUMMARY}

The experiment vás conducted at lhe Federal University of Santa Maria, RS, Brazil, during the 1984 growing season to determine lhe influence ofplanting dates on lhe yield of marketable bulbs and yield of bulb quality grades of 10 garlic (Ailium sativum L.) cultivars. Planting dates were April 27, May 18 and July 14. Planting dates influenced lhe average yield of marketable bulbs as wel! as the yield of bulb quality grades. Planting on May 18 effected the highest yields of marketable bulbs $m$ the experiment. The cultivars with the best performances were Gigante Lavinia, Gigante inconfidentes, São Lourenço e Quitéria.
Key words: garlic, cultivars, planting dates, yield, quality grades.

\section{INTRODUÇÃO}

Segundo maior consumidor mundial de alho (MARTINS, 1983), o Brasil é o maior importador mundial do produto (NADAL etaL, 1986). No Brasil, a época de colheita do alho varia com a região de produção, sendo mais tardia nos estados sulinos, aspecto importante para a ampliação do período de oferta no mercado interno (NADAL $\boldsymbol{e} t$ al., 1986).

$\mathrm{Na}$ produção de alho não basta o rendimento quantitativo, sendo necessária a identificação, através da pesquisa, de cultivares que, além do desempenho produtivo numa determinada região ou localidade, nela produzam bulbos com baixa incidência de defeitos (MUELLER \& BIASI, 1989).

O peso do bulbo da planta de alho, característica importante do ponto de vista comercial, é influenciado pelo tamanho da planta por ocasião do início da bulbificação, o qual tem fotoperíodo mínimo

\footnotetext{
${ }^{1}$ Engenheiro Agrônomo, Esp., Professor Adjunto, Departamento de Fitotecnia, Centro de Ciências Rurais (CCR), Universidade Federal de Santa Maria (UFSM), 97105-900, Santa Maria - RS. Autor para correspondência.

${ }^{2}$ Engenheiro Agrônomo, MSC. Professor Titular, Departamento de Fitotecnia, CCR, UFSM.

${ }^{3}$ Engenheiro Agrônomo, MSC. Professor Adjunto, Departamento de Fitotecnia, CCR, UFSM.
} 
crítico; e, pela duração do período de crescimento dos bulbos, dependente de condições do local de produção (GARCIA, 1989).

Cultivares de alho com grande número de bulbilhos por bulbo são considerados de baixo valor comercial (RESENDE et al, 1993). O alho importado da Argentina, Chile e Uruguai, intensamente comercializado no mercado brasileiro de janeiro a abril, tem bom aspecto e é muito competitivo (NADAL et al., 1986).

Os cultivares Gigantes Lavínia e Gigante Inconfidente de alho nobre de ciclo curto destacaram-se pela produção e peso de bulbos comerciais no Planalto Catarinense (MUELLER \& BIASI, 1989).

Os objetivos deste estudo foram avaliar o efeito de épocas de plantio no rendimento de bulbos comerciais de cultivares de alho em Santa Maria, RS, e identificar as cultivares com melhor potencial de rendimento quanti-qualitativo nas condições locais.

\section{MATERIAIS E MÉTODOS}

O experimento foi conduzido na Universidade Federal de Santa Maria, RS, no ano agrícola de 1984, em solo pertencente à unidade de mapeamento São Pedro.

$\mathrm{O}$ delineamento experimental usado foi o de blocos ao acaso com parcelas subdivididas, com quatro repetições. Nas parcelas utilizou-se três épocas de plantio: $27 / 4,18 / 5$ e $14 / 7$, nas subparcelas plantou-se as cultivares Chonan, Roxo Pérola de Caçador, Roxo Caxiense, Caçapava, Quitéria, Gigante Lavínia, São Lourenço, Gigante Inconfidentes, Dona Josefa e Regional.

As adubações de cultivo e de cobertura foram baseadas nas recomendações da rede oficial de laboratórios de análise de solo (FECOTRIGO, 1981) e de FILGUEIRA (1982). A adubação de cultivo, localizada nos sulcos longitudinais ao canteiro, constou de nitrogênio, fósforo, potássio e boro. As adubações nitrogenadas de cobertura foram realizadas aos 40 e 60 dias após a emergência das plantas.

Os bulbos utilizados como material propagativo pertenciam às classes 3 (médios) e 4 (pequenos). Após a debulha, os bulbilhos sofreram seleção, classificação e tratamento com PCNB a $0,5 \%$. Os bulbilhos, com peso de 1,0 a $2,0 \mathrm{~g}$, foram plantados manualmente, com o ápice voltado para cima, no espaçamento de $0,25 \times 0,10 \mathrm{~m}$. Nas subparcelas de $1,50 \times 1,95 \mathrm{~m}$ foram plantados 90 bulbilhos, e, posteriormente, colhidas 60 plantas, da área útil de $1,55 \mathrm{~m}^{2}$, para as amostragens.
Executou-se o manejo recomendado para a irrigação, escarificação, controle de ervas daninhas e controle fitossanitário. Suspendeu-se a irrigação duas semanas pré-colheita.

A colheita, manual, por arrancamento, realizada quando a parte aérea das plantas estava parcialmente seca, com 3 a 4 folhas apicais ainda verdes (GARCIA, 1989), estendeu-se do segundo decêndio de outubro até o primeiro decêndio de dezembro, dependendo da cultivar e da época de plantio.

Realizou-se a cura a campo e em galpão. Para a cura a campo, as plantas foram arranjadas em fileiras, com cobertura dos bulbos de cada fileira anterior pelas folhas das plantas da fileira imediatamente seguinte, permanecendo expostas ao sol durante três dias (EMBRAPA, 1991). Completou-se a cura dos bulbos em galpão: as plantas, em número de 30 a 40 , foram atadas em maços e estaleiradas durante 30 dias.

Nos bulbos curados, cortou-se a haste a 1 , $0 \mathrm{~cm}$ acima do bulbo e as raízes rente ao bulbo; as películas soltas e sujas foram retiradas. Os bulbos foram classificados de acordo com FILGUEIRA (1982) em: florão (diâmetro superior a $55 \mathrm{~mm}$ ); graúdo (diâmetro de 45 a menor que $55 \mathrm{~mm}$ ); médio (diâmetro de 35 a menor que $45 \mathrm{~mm}$ ); pequeno (diâmetro de 25 a menor que $35 \mathrm{~mm}$ ) e miúdo (diâmetro de 15 a menor que $25 \mathrm{~mm}$ ).

A pesagem foi feita por classe, considerando-se as cinco classes comerciais.

\section{RESULTADOS E DISCUSSÃO}

As épocas de plantio influenciaram o rendimento médio e o rendimento quanti-qualitativo de bulbos comerciais curados dos cultivares estudadas, efeito também verificado por GARCIA (1989) nos municípios de Pelotas e Pinheiro Machado, RS. A Tabela 1 mostra que o rendimento de bulbos comerciais diferiu significativamente, entre cultivares, nas três épocas de plantio. Em Caçador, SC, MUELLER \& BIASI (1989) também encontraram diferenças marcantes na produção de bulbos comerciais de diferentes cultivares plantadas na mesma época.

Comparativamente à produtividade média da cultura do alho no RS, de 3,0 toneladas por hectare, aproximadamente, no plantio de $27 / 4$, as cultivares apresentaram rendimento razoável, muito embora seu potencial produtivo houvesse sido apenas parcialmente expressado. A cultivar Gigante Inconfidente teve o melhor rendimento, o qual foi significativamente maior que o das demais cultivar. Não houve 
diferença significativa entre os rendimentos dos cultivares Gigantes Lavínia e Quitéria, os quais foram significativamente superiores aos das demais cultivares estudadas.

Tabela 1 - Rendimento médio (kg/ha) de bulbos comerciais curados de dez cultivares de alho em três épocas de plantio, Santa Maria, RS, 1984.

Rendimento de bulbos comerciais

Cultivares

Épocas de plantio

\begin{tabular}{lccc}
\hline & $27 / 4$ & $18 / 5$ & $14 / 7$ \\
Chonan & $6.737 \mathrm{c}^{*}$ & $8.821 \mathrm{e}$ & $4.069 \mathrm{~d}$ \\
Roxo Pérola de Caçador & $6.477 \mathrm{~cd}$ & $9.814 \mathrm{de}$ & $5.486 \mathrm{c}$ \\
Roxo Caxiense & $7.044 \mathrm{c}$ & $10.228 \mathrm{~cd}$ & $7.069 \mathrm{~b}$ \\
Caçapava & $6.061 \mathrm{~cd}$ & $8.418 \mathrm{e}$ & $4.108 \mathrm{~cd}$ \\
Quitéria & $8.562 \mathrm{~b}$ & $11.212 \mathrm{bc}$ & $7.870 \mathrm{~b}$ \\
Gigante Lavínia & $8.719 \mathrm{~b}$ & $11.854 \mathrm{ab}$ & $7.235 \mathrm{~b}$ \\
São Lourenço & ------- & $12.756 \mathrm{a}$ & $9.579 \mathrm{a}$ \\
Gigante Inconfidentes & $10.929 \mathrm{a}$ & $11.888 \mathrm{ab}$ & $4.268 \mathrm{~cd}$ \\
Dona Josefa & $5.428 \mathrm{~d}$ & $6.293 \mathrm{f}$ & $4.309 \mathrm{~cd}$ \\
Regional & ------- & $6.377 \mathrm{f}$ & $8.544 \mathrm{ab}$ \\
& & & \\
\hline
\end{tabular}

* Médias seguidas de mesma letra na coluna não diferm significativamente entre si pelo teste de Duncan em nível de 5\% de propabilidade.

O plantio de 18/5 agregou incremento no rendimento de bulbos comerciais de todas as cultivares estudadas. O rendimento de a cultivar São Lourenço, o mais alto nesta época de plantio, não diferiu significativamente do rendimento dos cultivares Gigante Inconfidentes e Gigante Lavínia, de ciclo mais curto, nem do rendimento da cultivar Quitéria.

Comparativamente às épocas de plantio anteriores, o plantio de 14/7 reduziu o rendimento de bulbos comerciais de todas as cultivares testadas exceto o do alho regional. Reduções análogas também foram encontradas por GARCIA (1989). À semelhança do que ocorreu nas épocas de plantio anteriores, as cultivares Gigantes Lavínia e Quitéria responderam de modo similar ao plantio de 14/7, tendo sido seu rendimento superado apenas pelo da cultivar São Lourenço. A dificuldade de conservação do alho semente e a brotação dos bulbilhos dificultam os plantios tardios, podendo inviabilizá-los, como também observou GARCIA (1989).

$\mathrm{O}$ efeito das três épocas de plantio no rendimento, por classe de bulbos comerciais, das dez cultivares estudadas, é mostrado na Tabela 2. No plantio de 27/4, seis cultivares apresentaram o maior rendimento de bulbos médios. O plantio de $18 / 5$ aumentou o rendimento de bulbos médios de sete das dez cultivares estudadas, o qual foi também o mais alto dentre as classes comerciais de bulbos. A cultivar Gigante Lavínia apresentou o maior rendimento de bulbos graúdos, tendo sido a única cultivar a produzir bulbos florão, também nesta época de plantio. No plantio de 14/7, houve redução no rendimento de bulbos médios $\mathrm{e}$ aumento no rendimento de bulbos pequenos.

Todas as cultivares estudadas sofreram efeito das épocas de plantio. Gigante Lavínia e Gigante Inconfidentes, cultivares mais precoces, tiveram os maiores rendimentos de bulbos graúdos e médios, os quais corresponderam, respectivamente, a $85 \%$ e $88 \%$ do rendimento total de bulbos comerciais no plantio de $18 / 5$. São Lourenço e Quitéria, cultivares um pouco mais tardias, tiveram rendimentos de bulbos graúdos e médios correspondentes, respectivamente, a $92 \%$ e $85 \%$ do seu rendimento total de bulbos comerciais, na segunda época de plantio.

O peso médio dos bulbos das cultivares estudadas foi influenciado pela época de plantio. Os dados apresentados na Tabela 3 mostram que, comparativamente ao plantio de 27/4, houve aumento do peso médio dos bulbos no plantio de $18 / 5$, o que contribuiu para as diferenças significativas encontradas no rendimento de bulbos comerciais. Com exceção do alho regional, os demais cultivares produziram bulbos menores no plantio de $14 / 7$, sendo mais acentuadas as reduções de peso médio sofridas pelos cultivares nobres de ciclo curto Gigante Lavínia e Gigante Inconfidente. 
Tabela 2 - Rendimento médio (\%) por classe de bulbos comerciais curados de dez cultivares de alho em três épocas de plantio, Santa Maria, RS, 1984.

\begin{tabular}{|c|c|c|c|c|c|c|}
\hline \multirow{2}{*}{ Cultivares } & \multirow{2}{*}{$\begin{array}{l}\text { Épocas de } \\
\text { plantio }\end{array}$} & \multicolumn{5}{|c|}{ Rendimento médio por classe } \\
\hline & & Florão & Graúdo & Médio & Pequeno & Miúdo \\
\hline Chonan & $\begin{array}{l}27 / 4 \\
18 / 5 \\
14 / 7\end{array}$ & $\begin{array}{l}- \\
- \\
-\end{array}$ & $\begin{array}{c}- \\
5,58 \\
-\end{array}$ & $\begin{array}{l}55,32 \\
66,92 \\
27,67\end{array}$ & $\begin{array}{l}42,82 \\
26,56 \\
52,45\end{array}$ & $\begin{array}{c}1,86 \\
0,94 \\
19,88\end{array}$ \\
\hline $\begin{array}{l}\text { Roxo Pérola de } \\
\text { Caçador }\end{array}$ & $\begin{array}{l}27 / 4 \\
18 / 5 \\
14 / 7\end{array}$ & $\begin{array}{l}- \\
- \\
-\end{array}$ & $\begin{array}{c}8,49 \\
15,04 \\
0,77\end{array}$ & $\begin{array}{l}47,49 \\
57,43 \\
26,14\end{array}$ & $\begin{array}{l}40,16 \\
26,59 \\
64,90\end{array}$ & $\begin{array}{l}3,86 \\
0,94 \\
8,20\end{array}$ \\
\hline Roxo Caxiense & $\begin{array}{l}27 / 4 \\
18 / 5 \\
14 / 7\end{array}$ & $\begin{array}{l}- \\
- \\
-\end{array}$ & $\begin{array}{c}4,97 \\
11,00 \\
4,71\end{array}$ & $\begin{array}{l}54,91 \\
72,13 \\
46,94\end{array}$ & $\begin{array}{l}38,34 \\
16,79 \\
47,53\end{array}$ & $\begin{array}{l}1,77 \\
0,08 \\
0,82\end{array}$ \\
\hline Caçapava & $\begin{array}{l}27 / 4 \\
18 / 5 \\
14 / 7\end{array}$ & $\begin{array}{l}- \\
- \\
-\end{array}$ & $\begin{array}{c}- \\
6,43 \\
2,63\end{array}$ & $\begin{array}{l}40,85 \\
64,17 \\
16,63\end{array}$ & $\begin{array}{l}54,83 \\
29,00 \\
75,68\end{array}$ & $\begin{array}{l}4,82 \\
0,39 \\
5,06\end{array}$ \\
\hline Quitério & $\begin{array}{l}27 / 4 \\
18 / 5 \\
14 / 7\end{array}$ & $\begin{array}{l}- \\
-\end{array}$ & $\begin{array}{c}8,85 \\
16,65 \\
11,96\end{array}$ & $\begin{array}{l}58,32 \\
68,48 \\
60,30\end{array}$ & $\begin{array}{l}31,74 \\
14,35 \\
27,53\end{array}$ & $\begin{array}{l}1,08 \\
0,52 \\
0,21\end{array}$ \\
\hline Gigante Lavínia & $\begin{array}{l}27 / 4 \\
18 / 5 \\
14 / 7\end{array}$ & $\begin{array}{c}- \\
5,55 \\
-\end{array}$ & $\begin{array}{c}12,04 \\
45,86 \\
1,84\end{array}$ & $\begin{array}{l}45,60 \\
40,09 \\
31,68\end{array}$ & $\begin{array}{c}41,98 \\
8,48 \\
66,47\end{array}$ & $\begin{array}{c}0,39 \\
- \\
-\end{array}$ \\
\hline São Lourenço & $\begin{array}{l}27 / 4 \\
18 / 5 \\
14 / 7\end{array}$ & $\begin{array}{l}- \\
-\end{array}$ & $\begin{array}{c}- \\
16,67 \\
8,96\end{array}$ & $\begin{array}{c}- \\
75,88 \\
74,83\end{array}$ & $\begin{array}{c}- \\
7,45 \\
16,27\end{array}$ & $\begin{array}{c}- \\
- \\
0,44\end{array}$ \\
\hline $\begin{array}{l}\text { Gigante Incon- } \\
\text { fidentes }\end{array}$ & $\begin{array}{l}27 / 4 \\
18 / 5 \\
14 / 7\end{array}$ & $\begin{array}{l}- \\
- \\
-\end{array}$ & $\begin{array}{c}24,03 \\
25,31 \\
-\end{array}$ & $\begin{array}{l}53,77 \\
63,19 \\
12,30\end{array}$ & $\begin{array}{l}21,97 \\
11,43 \\
76,94\end{array}$ & $\begin{array}{c}0,23 \\
0,07 \\
10,75\end{array}$ \\
\hline Dona Josefa & $\begin{array}{l}27 / 4 \\
18 / 5 \\
14 / 7\end{array}$ & $\begin{array}{l}- \\
- \\
-\end{array}$ & $\begin{array}{c}4,75 \\
8,60 \\
-\end{array}$ & $\begin{array}{l}38,74 \\
41,19 \\
25,13\end{array}$ & $\begin{array}{l}47,75 \\
47,56 \\
65,40\end{array}$ & $\begin{array}{l}8,75 \\
2,65 \\
9,47\end{array}$ \\
\hline & $\begin{array}{l}27 / 4 \\
18 / 5 \\
14 / 7\end{array}$ & $\begin{array}{l}- \\
- \\
-\end{array}$ & $\begin{array}{c}- \\
6,92 \\
6,62\end{array}$ & $\begin{array}{c}- \\
43,01 \\
51,32\end{array}$ & $\begin{array}{c}- \\
48,50 \\
42,05\end{array}$ & $\begin{array}{c}- \\
1,57 \\
-\end{array}$ \\
\hline
\end{tabular}

Tabela 3 - Peso médio (g) de bulbos curados de dez cultivares de alho em três épocas de plantio, Santa Maria, RS, 1984.

\begin{tabular}{lccc}
\hline & \multicolumn{3}{c}{ Épocas de plantio } \\
\cline { 2 - 4 } & $27 / 4$ & $18 / 5$ & $14 / 7$ \\
\hline Chonan & & 22,47 & 10,41 \\
Roxo Pérola de Caçador & 17,17 & 24,85 & 13,70 \\
Roxo Caxiense & 16,79 & 26,60 & 13,66 \\
Caçapava & 18,62 & 24,06 & 13,39 \\
Quitéria & 16,91 & 28,35 & 19,66 \\
Gigante Lavínia & 21,58 & 38,58 & 18,79 \\
São Lourenço & 27,47 & 32,48 & 25,68 \\
Gigante Inconfidentes & - & 33,91 & 12,18 \\
Dona Josefa & 29,53 & 19,79 & 14,05 \\
Regional & 15,72 & 20,18 & 22,77 \\
& - & & \\
\hline
\end{tabular}

\section{AGRADECIMENTOS}

Os autores agradecem à EMBRAPA/CNPH, EMPASC/E. E. DE CAÇADOR, EMATER/RS SANTA MARIA - PELOTAS - SÃO LOURENÇO, AFUBRA, AGAPA, COOPERATIVA CAXIENSE E CAÇAPAVANA pela doação e/ou remessa de alho-semente; a SANDOZ DO BRASIL e UNION CARBIDE DO BRASIL pela doação de defensivos agrícolas, e ao professor Valduino Estefanel pela análise estatística dos dados. 


\section{REFERÊNCIAS BIBLIOGRÁFICAS}

EMBRAPA-CNPH, EMATER-RS. Cultura do alho. Pelotas. 1991. 6p. Sistema Simplificado de Produção, 4.

FECOTRIGO. Manual de adubação e calagem para cultivos agrícolas do Rio Grande do Sul e Santa Catarina. Porto Alegre, 1981.34 p. Trigo e soja, 56.

FILGUEIRA, F.A.R. Manual de olericultura. 2. ed. São Paulo: "Ceres", 1982. 2 v. v. 2. Cap. 5: Aliásseis I: p. 105-142.

GARCIA, A. Épocas de plantio para a cultura do alho no Rio Grande do Sul. EMBRAPA: CNPFT. 1989. 21 p. Boletim de Pesquisa, 15.
MARTINS, M.E. Mais alho para consumo. Casa da Agricultura, Campinas, v. 5, n. 2. p. 14-17, mareo-abril. 1983.

MUELLER, S., BIASI, J. Comportamento de cultivares de alho no Planalto Catarinense. Horticultura Brasileira, Brasília, v. 7, n. 1,p.7-9, 1989.

NADAL, R. de, GUIMARÃES, D.R, BIASI, J., et al. Olericultura em Santa Catarina: aspectos técnicos e econômicos. Florianópolis: DID/EMPASC, 1986. 187 p.

RESENDE, G.M. de. Comportamento de cultivares de alho (Ailium salivam L.) no Norte de Minas Gerais. Horticultura Brasileira. Brasília, v. 11, n. 1, p. 93, 1993. 